\title{
MOTIVASI PENGUASAAN BAHASA MANDARIN PADA PELAJAR DAN MAHASISWA KOTA PONTIANAK
}

\author{
Ina \\ Fakultas Keguruan Dan Ilmu Pedidikan Universitas Tanjungpura, Pontianak \\ Email korespondensi:chenyenna@gmail.com
}

\begin{abstract}
ABSTRAK
Pada saat ini Bahasa Mandarin telah menjadi salah satu bahasa yang wajib untuk dikuasai agar mampu bersaing dalam persaingan global. Namun, Bahasa Mandarin merupakan salah satu mata pelajaran yang kurang disukai oleh para pelajar, karena dianggap susah untuk dipelajari. Motivasi merupakan salah satu faktor yang penting untuk memastikan hasil pembelajaran dapat berjalan dengan lancar dan memperoleh hasil yang telah ditentukan sebelumnya. Menurut rekapitulasi data peserta pretest HSK yang diselenggarakan oleh Hanban, RRT di Pontianak pada tahun 2015, terdapat 43 sekolah dari tingkat SD - SMA/SMK yang mengikuti simulasi ujian HSK. Penelitian ini dilakukan dengan menyebarkan kuesioner kepada 175 responden yang terdiri dari empat (4) kelompok responden. Hasil penelitian menunjukkan bahwa faktor motivasi ekstrinsik mempunyai peranan yang sangat penting dalam memotivasi para pelajar untuk menguasai Bahasa Mandarin. Perkembangan perekonomian dan persaingan global menjadikan pembelajaran Bahasa Mandarin menjadi kebutuhan bagi setiap orang yang ingin meningkatkan kompetensi dirinya. Faktor instrinsik ketertarikan dan minat menjadi motivasi awal dan pendukung yang mendorong para pelajar dan mahasiswa untuk mencoba memahami dan mempelajari Bahasa Mandarin.
\end{abstract}

Kata kunci : Bahasa Mandarin, motivasi, faktor instrinsik, faktor ekstrinsik

\section{Pendahuluan}

Pembelajaran Bahasa Mandarin seringkali dianggap rumit bagi sebagian siswa, karena dari segi pelafalan dan karakter hurufnya, Bahasa Mandarin sangat berbeda dengan Bahasa Indonesia. Dari segi pelafalan, Bahasa Mandarin harus dilafalkan dengan menggunakan nada yang 
berbeda, dimana perubahan nada dapat menyebabkan perubahan arti. Dari segi karakter huruf, huruf BahasaMandarin berasal dari huruf piktograf yang menyiratkan arti dan pelafalan. Salah satu contoh perbedaan dari segi tata bahasa adalah Bahasa Mandarin mempunyai kata bilangan yang jumlahnya sangat banyak, pola kalimat yang tidak dimiliki dalam Bahasa Indonesia misalnya struktur kalimat "ba", dll. Dari segi morfologi, pembentukan kosakata Bahasa Mandarin dipengaruhi oleh adat istiadat dan budaya Tiongkok yang telah terbentuk sejak ribuan tahun yang lalu.

Oleh karena itu motivasi merupakan salah satu faktor yang penting untuk mempengaruhi perilaku dan prestasi individu untuk mempelajari Bahasa Mandarin.

Belajar merupakan suatu proses yang diperlukan untuk meningkatkan kemampuan beradaptasi terhadap lingkungan. Proses belajar diharapkan dapat dilakukan melalui proses yang efektif dan efisien dan mencapai hasil pembelajaran yang telah ditentukan sebelumnya. Namun, kadangkala proses belajar bukanlah sesuatu yang mudah, sehingga diperlukan motivasi yang kuat agar dapat konsisten mengikuti proses belajar dan mendapatkan hasil yang maksimal. Proses pembelajaran yang berhasil bukan hanya dipengaruhi oleh kualitas pendidik, bahan ajar dan fasilitas pendukungnya, namun siswa didik sebagai subyek belajar merupakan faktor penting dalam pencapaian hasil. Seringkali pendidik menemukan ada siswa didik yang prestasinya kurang baik bukan karena memiliki tingkat kecerdasan yang kurang, namun disebabkan oleh kurangnya motivasi untuk belajar. Motivasi akan mendorong perilaku dalam bentuk nyata. Motivasi yang kuat akan mendorong peserta didik untuk berusaha meningkatkan kemampuannya dalam belajar.

Di dalam kehidupan masyarakat Indonesia sendiri penggunaan Bahasa Mandarin baru mulai dirasakan urgensinya dengan adanya MEA dan semakin intensnya kerjasama dalam berbagai bidang antara pemerintah Indonesia dan RRT.

\section{Definisi Motivasi}

Menurut Jeanne Ellis Ormrod (2008), motivasi adalah sesuatu yang menghidupkan (energize), mengarahkan dan mempertahankan perilaku. Sedangkan Arends (2009) mndefinisikan motivasi sebagai proses yang 
merangsang tindakan dan sesuatu yang memicu manusia untuk bertindak. Bahasa Mandarin menggunakan huruf Han dan setiap huruf mempunyai pelafalan dengan 4 (empat) jenis nada yang mempengaruhi arti dari kata yang dibentuk dari huruf-huruf tersebut. Oleh karena itu, sebagian siswa yang mempelajari Bahasa Mandarin menganggap bahasa ini merupakan suatu bahasa yang sulit dipelajari apabila dibandingkan dengan Bahasa Inggris atau bahasa asing lainnya yang menggunakan huruf latin dan nada setiap kata tidak memiliki perubahan arti. Oleh karena itu diperlukan sesuatu hal yang dapat merangsang dan memicu siswa untuk mempelajari bahasa Mandarin secara serius.

\section{Teori Motivasi}

Mengutip dari Ormrod (2008), motivasi menentukan tujuan-tujuan spesifik yang menjadi arah usaha siswa (Maerh \& Meyer 1997; Pinritch at, al., 1993), sehingga motivasi dapat mempengaruhi pilihan yang dibuat oleh siswa. Misalnya siswa yang kesulitan belajar bahasa Mandarin karena sulit melafalkan nada-nada setiap huruf dengan tepat. Siswa tersebut dapat memilih untuk menyerah atau dapat bertahan dengan belajar dengan lebih keras lagi. Pilihan mana yang akan diambil oleh si pelajar tersebut tergantung pada motivasi yang dimilikinya. Sekuat apapun guru, orangtua maupun teman-temannya memberikan semangat, namun apabila siswa yang bersangkutan tidak mempunyai motivasi belajar, semua hal tersebut akan menjadi sia-sia. Sebagaimana dirangkum oleh Ormrod, motivasi dapat mengarahkan perilaku ke tujuan tertentu, meningkatkan usaha dan energi, meningkatkan prakarsa (inisiasi) dan kegigihan terhadap berbagai aktivitas, mempengaruhi proses-proses kognitif, menentukan konsekuensi mana yang memberikan penguatan dan menghukum serta meningkatkan performa.

Menurut Teori Evaluasi Kognitif, motivasi dapat dibagi menjadi 2 jenis, yaitu motivasi ekstrinsik dan motivasi instrisik. Motivasi ekstinsik disebabkan oleh faktor-faktor eksternal individu dan tidak berkaitan dengan tugas yang sedang dilakukan, misalnya minat, prestasi, rasa tanggung jawab dan kompetensi diri. Sedangkan motivasi intrinsik adalah motivasi yang timbul oleh faktor-faktor dari dalam dirinya atau melekat dengan tugas yang sedang dilakukan. Dalam teori penguatan, motivasi 
timbul akibat stimulus-stimulus dari luar yang mengalami penguatan sehingga mendorong seseorang untuk bertindak. Motivasi dapat dibedakan menjadi penguatan positif (positive reinforcement) dan penguatan negative (negative reinforcement). Menurut Arends (2009) penguatan positif timbul setelah adanya perilaku yang diinginkan muncul, menyebabkan naiknya kemungkinan pengulangan perilaku tersebut, misalnya nilai yang baik, pujian atau hak khusus. Sedangkan penguatan negatif pengurangan penguatan yang diakibatkan oleh perilaku tertentu, misalnya nilai jelek, hukuman atau kehilangan hak tertentu. Berdasarkan pada teori kebutuhan Maslow, beberapa penulis seperti David McClelland, Atkinson dan Feather, Alschuler, Tabor an Mclntyre merumuskan teori kebutuhan yang lebih spesifik dalam dunia pendidikan, yaitu teori disposisi kebutuhan (needs disposition theory), yang menyatakan bahwa perilaku seseorang dilakukan untuk mencapai prestasi, afiliasi dan pengaruh. Teori pembelajaran sosial menyatakan bahwa motivasi timbul ekspektasi individu tentang kesempatannya untuk mencapai tujuan dan nilai atau tingkat kepuasan akan tujuan yang telah dicapainya.

Penelitian motivasi yang dilakukan oleh Yi Ying, dkk (2013) terhadap mahasiswa tingkat satu pada perguruan tinggi jurusan Bahasa Mandarin di 3 (tiga) perguruan tinggi yang menyelenggarakan pendidikan Bahasa Mandarin. Perguruan tinggi tersebut yaitu Universitas Bina Nusantara Jakarta, Universitas Sumatera Utara Medan, dan Universitas Darma Persada Jakarta menunjukkan hasil bahwa motivasi subyek penelitian untuk mempelajari Bahasa Mandarin sebagai bahasa kedua relatif rendah. Tidak ada perbedaan yang signifikan antara motivasi integratif maupun instrumental pada responden dalam mempelajari Bahasa Mandarin sebagai bahasa kedua. Namun motivasi intensitas relatif lebih tinggi dibandingkan dengan motivasi integratif maupun intrumental. Meskipun tidak ada perbedaan yang signifikan antara responden yang berasal dari keturunan Tionghoa maupun non-Tionghoa dalam mempelajari Bahasa Mandarin, namun responden mahasiswa nonTionghoa relatif lebih termotivasi dalam mempelajari bahasa Mandarin sebagai bahasa kedua. Yovita (2014) dalam thesisnya mempelajari kondisi pembelajaran Bahasa Mandarin di Universitas Bunda Maria serta mentabulasikan saran-saran mahasiswa terhadap perbaikan pembelajaran. 
Dengan menggunakan wawancara langsung, penulis juga mengumpulkan informasi mengenai motivasi yang mendorong mahasiswa untuk belajar Bahasa Mandarin di Universitas Bunda Maria. Namun hasil penelitian belum mengklasifikasikan motivasi apa yang paling dominan. Lü Peishan (2013) menyebarkan 534 siswa dari 5 sekolah di Bandung menyimpulkan bahwa 56\% siswa merasa pelajaran Bahasa Mandarin merupakan mata pelajaran yang menyenangkan, pembelajaran Bahasa Mandarin masih berkaitan dengan melestarikan budaya bangsa, dan ada hubungan lurus antara waktu belajar dan minat belajar. Lin Xin (2013) dalam penelitiannya thesisnya menyimpulkan bahwa motivasi mahasiswa dapat dikategorikan menjadi 3 jenis, yaitu motivasi instrinsik, motivasi sebagai alat dan motivasi ekstrinsik. Urutan dominasi ketiga motivasi ini berbedabeda sesuai dengan tingkatannya.

\section{Metode Penelitian}

Bahasa merupakan wujud dan bentuk dari budaya suatu bangsa, sehingga ada sebagian masyarakat yang menganggap bahwa bahasa Mandarin merupakan bahasa etnik yang dipelajari oleh suku bangsa tertentu saja. Namun pada saat ini telah ada banyak sekolah yang mengadakan pelajaran Bahasa Mandarin di sekolah mulai dari tingkat pra sekolah sampai dengan sekolah tingkat menengah. Menurut rekapitulasi data sekolah peserta pretest HSK tahun 2015 yang diselenggarakan Hanban RRT dan Badan Koordinasi Pendidikan Bahasa Mandarin Kalbar sebagai pelaksana, terdapat 43 sekolah tingkat SD - SMA di Pontianak yang menyelenggarakan pelajaran Bahasa Mandarin disekolahnya, diantaranya 14 sekolah setingkat SMA/SMK dan 12 sekolah setingkat SMP dan 17 Sekolah Dasar. Pendidikan Bahasa Mandarin di tingkat pendidikan tinggi diselenggarakan oleh Fakultas Keguruan dan Ilmu Pendidikan Universitas Tanjungpura mulai pada tahun 2009. Program studi ini sampai dengan saat ini telah meluluskan 51 dan persentasi mahasiswa berlatarbelakang suku non tionghoa mencapai $75 \%$.

Subyek penelitian ini terdiri dari 4 (empat) kelompok peserta didik. Total responden sebanyak 175 peserta didik, yang terdiri dari 75 siswa pada sekolah SMA Santu Petrus dan SMA Negeri 3 Pontianak serta 100 mahasiswa pada program studi pendidikan Bahasa Mandarin FKIP dan 
program studi bukan jurusan Bahasa Mandarin (program studi Hubungan Internasional FISIP Universitas Tanjungpura dan Akademi Analisis Kesehatan Pontianak).

Penelitian ini bertujuan untuk mengetahui motivasi para pelajar dan mahasiswa di Pontianak dalam mempelajari Bahasa Mandarin, agar guru dan dosen dapat memperoleh informasi awal mengenai latar belakang dan motif belajar mahasiswa sehingga dapat menentukan strategi belajar yang tepat demi keefektifan proses pembelajaran.

Penelitian dilakukan dengan membagikan kuesioner kepada responden. Kuesioner berisi 3 bagian utama yaitu identitas diri, bahasa yang dikuasai dan lingkungan berbahasa dan motivasi mempelajari bahasa Mandarin.

\section{Hasil dan Pembahasan}

Jumlah total responden sebanyak 175 terdiri dari:

\begin{tabular}{|c|c|c|}
\hline ASAL SEKOLAH & $\begin{array}{c}\text { JUMLAH } \\
\text { RESPONDEN }\end{array}$ & $\begin{array}{l}\text { PERSENTASE } \\
(\%)\end{array}$ \\
\hline Prodi Pendidikan Bahasa Mandarin FKIP & 64 & 36.57 \\
\hline $\begin{array}{l}\text { Prodi Hubungan Internasional FISIP \& Akademi } \\
\text { Analisis Kesehatan Pontianak }\end{array}$ & 36 & 20.57 \\
\hline SMA Negeri 3 & 33 & 18.86 \\
\hline SMA Santu Petrus & 42 & 24 \\
\hline Total & 175 & 100 \\
\hline
\end{tabular}

Tabel 1 Informasi Umum Responden

Berdasarkan tabel 1 diatas, kita mendapatkan informasi bahwa 57,14\% responden merupakan mahasiswa yang belajar Bahasa Mandarin di tingkat perguruan tinggi dan 42,86\% responden merupakan peserta didik yang belajar bahasa Mandarin di tingkat sekolah menengah. Bahasa Mandarin merupakan muatan utama pada program studi Pendidikan Bahasa Mandarin, sedangkan pada prodi Hubungan Internasional dan Akademi Analisis Kesehatan, mata kuliah Bahasa Mandarin merupakan mata kuliah pilihan. Pada tingkat sekolah menengah, pelajaran bahasa Mandarin merupakan mata pelajaran wajib, dengan jumlah jam belajar 2-3 sks per minggu, namun bukan merupakan mata pelajaran 
inti. Dari total responden diatas, $72 \%$ responden berlatar belakang etnik non tionghoa.

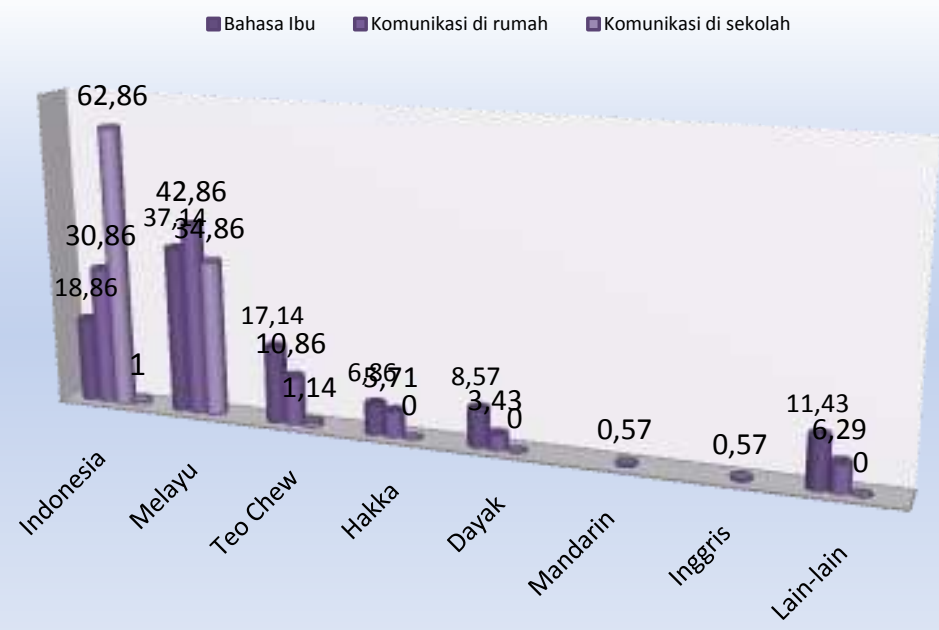

Grafik 1 Bahasa Komunikasi Responden

Grafik 1 menunjukkan bahwa bahasa ibu sebagian besar responden adalah Bahasa Melayu dan Bahasa Indonesia. Bahasa komunikasi yang digunakan di rumah maupun di sekolah atau di kampus didominasi oleh Bahasa Melayu dan Bahasa Indonesia. Meskipun di sekolah atau kampus mengajarkan Bahasa Mandarin maupun Bahasa Inggris, namun hanya masing-masing 0,57\% peserta didik yang menggunakan kedua bahasa asing ini dalam komunikasi.

$2 \% 0 \% \quad 0 \% \quad 2 \% 1 \% 0 \%$
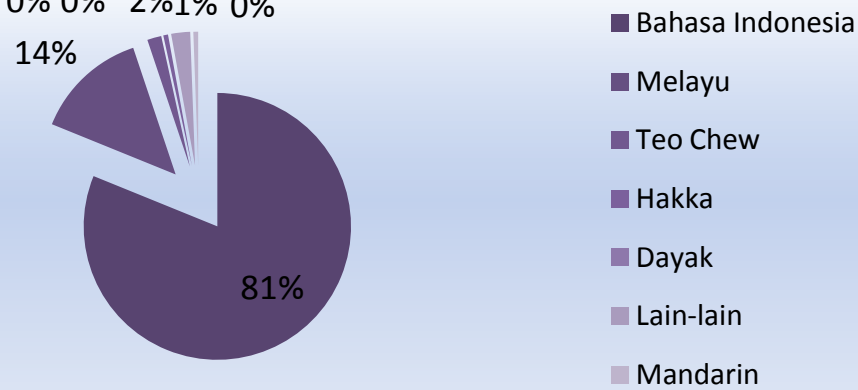
Grafik 2 Kemampuan Berbahasa Asing Responden

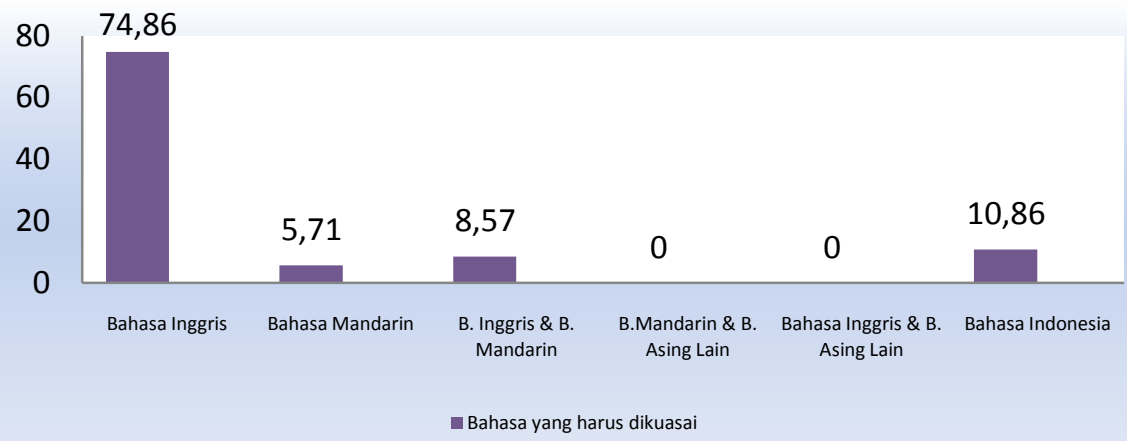

Grafik 3 Kompetensi Bahasa Pendukung Pekerjaan

Perkembangan ekonomi dunia internasional mendorong semakin eratnya kerjasama ekonomi Indonesia dengan negara-negara lain, baik di kawasan ASEAN, Asia, Eropa, dll. Nilai investasi asing di Kalimantan Barat sampai dengan September 2015 telah terealisasi senilai Rp14,89 triliun, yang berasal dari negara Singapura (38.7\%), Malaysia (37.9\%), RRT (2.6\%), Hongkong (0.3\%), dll sebanyak 110 proyek.

Dilihat dari grafik 2 dan 3, para responden menyadari pentingnya penguasaan bahasa asing namun kemampuan bahasa asing yang dimiliki oleh para responden masih minim dan ada kecenderungan untuk mempelajari Bahasa Inggris dibandingkan dengan Bahasa Mandarin maupun bahasa asing lainnya.

\begin{tabular}{|c|c|c|c|c|c|c|c|}
\hline 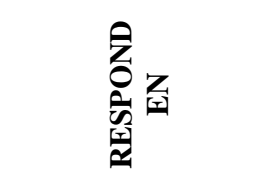 &  & 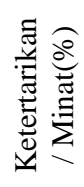 & 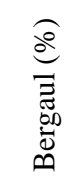 & 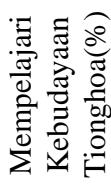 & 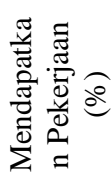 & 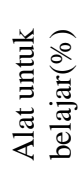 & 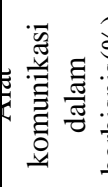 \\
\hline $\begin{array}{l}\text { PRODI B.MAN } \\
\text { (FKIP) }\end{array}$ & 6 & 30 & 3 & 6 & 27 & 25 & 3 \\
\hline PRODI NON MAN & 4.73 & 33.78 & 9.46 & 2.03 & 34.46 & 15.54 & 0 \\
\hline SMA NEGERI (3) & 2.13 & 21.28 & 9.57 & 5.32 & 37.23 & 11.7 & 12.77 \\
\hline $\begin{array}{c}\text { SMA SWASTA } \\
\text { (PETRUS) }\end{array}$ & 7.34 & 14.68 & 10.09 & 5.5 & 30.28 & 17.43 & 14.68 \\
\hline RATA-RATA & 5.05 & 24.94 & 8.03 & 4.71 & 32.24 & 17.42 & 7.61 \\
\hline
\end{tabular}

Tabel 2 Tabulasi Kecenderungan Motivasi Pelajar dan Mahasiswa Bahasa Mandarin di Pontianak 
Tabel 2 menunjukkan motivasi yang mendorong pelajar SMA dan mahasiswa Perguruan Tinggi untuk mempelajari bahasa Mandarin cenderung dipengaruhi oleh faktor dari luar, yaitu untuk mencari pekerjaan. Apabila kita cermati dengan lebih teliti, mahasiswa yang belajar di program studi yang bermuatan kompetensi bahasa Mandarin mempunyai motivasi instrinsik yang lebih kuat dibandingkan dengan ketiga kelompok responden lainnya. Ketertarikan dan minat mahasiswa terhadap bahasa Mandarin dan seni budaya yang terkait membuat mahasiswa tersebut melanjutkan studinya ke bidang bahasa Mandarin. Ketertarikan dan minat ini didukung oleh 2 (dua) motivasi ekstrinsik lainnya yaitu menggunakan Bahasa Mandarin sebagai alat untuk mendapatkan pengetahuan dan menjadikan Bahasa Mandarin dan pengetahuan yang dikuasai untuk mendapatkan pekerjaan yang ideal. Dalam ketiga kelompok responden lainnya, motivasi ekstrinsik untuk mendapatkan pekerjaan yang ideal melalui penguasaan bahasa Mandarin menjadi motivasi yang paling utama, namun motivasi instrinsik ketertarikan atau minat dan motivasi ekstrinsik bahasa sebagai alat untuk mempelajari pengetahuan dan bahasa sebagai alat komunikasi dalam berbisnis juga mempunyai peranan yang cukup signifikan dalam memotivasi para pelajar untuk menguasai bahasa Mandarin. Motivasi yang dimiliki oleh para pelajar bahasa Mandarin di Pontianak cenderung diakibatkan oleh stimulus dari luar, misalnya meningkatnya kebutuhan tenaga kerja yang memiliki kompetensi berbahasa asing, termasuk kompetensi berbahasa Mandarin, meningkatkan minat untuk belajar ke luar negeri dan tuntutan era keterbukaan dalam berbagai bidang terutama di bidang ekonomi dan bisnis. Stimulus dari luar mengakibatkan terbentuknya kebutuhan untuk mempelajari bahasa asing terutama bahasa negaranegara maju dan negara-negara yang menjalin kerjasama ekonomi dan perdagangan yang intens dengan Indonesia. Adanya ekspektasi individu pelajar untuk dapat bersaing dalam dunia kerja merupakan dorongan atau motivasi terbesar dalam mempelajari bahasa Mandarin.

Bahasa Mandarin bukan lagi menjadi bahasa milik suku bangsa tertentu yang digunakan dalam lingkungan suku bangsa itu saja, namun kini bahasa Mandarin mulai memposisikan dirinya sebagai bahasa asing yang wajib dipelajari sebagaimana layaknya bahasa Inggris, apabila anda mau mendapatkan pekerjaan yang layak dengan mudah.

\section{KESIMPULAN}

Motivasi merupakan salah satu faktor yang penting untuk mempengaruhi perilaku dan prestasi individu untuk melakukan suatu kegiatan atau tindakan. Demikian pula sewaktu kita mempelajari Bahasa Mandarin. Hasil pembelajaran yang maksimal bukan hanya ditentukan oleh kualitas pengajar, bahan 
pembelajaran, proses pembelajaran, fasilitas pembelajaran dan lingkungan berbahasanya, namun juga dipengaruhi oleh motivasi belajar si pelajar.

Motivasi dapat timbul dari dalam dirinya individu itu sendiri (instrinsik) maupun dari luar dirinya (ekstrinsik). Motivasi instrinsik tentunya lebih kuat dibandingkan dengan motivasi ekstrinsik, karena dorongan untuk belajar timbul dari dalam dirinya. Namun pada saat ini, tuntutan dunia pendidikan dan kerja yang merupakan bagian dari motivasi ekstrinsik memberikan pengaruh yang lebih besar dibandingkan dengan faktor instrinsik.

Hasil penelitian pada 4 (empat) kelompok pelajar bahasa Mandarin menunjukkan bahwa faktor ekstrinsik seperti kebutuhan untuk mempelajari bahasa Mandarin sebagai alat untuk meningkatkan kompetensi diri agar dapat memperoleh pengetahuan atau melanjutkan studi ke jenjang yang lebih tinggi dan mendapatkan pekerjaan yang ideal menjadi motivasi yang paling utama yang mendorong para mahasiswa atau pelajar mempelajari Bahasa Mandarin. Faktor instrinsik ketertarikan akan keunikan bahasa Mandarin dan minat dalam belajar Bahasa Mandarin menjadi suatu motivasi awal yang mendorong pelajar dan mahasiswa untuk mengenal dan memperdalam kemampuan berbahasa Mandarin. Empat (4) kelompok responden menunjukkan kecenderungan mempunyai motivasi yang searah, walaupun ke empat kelompok responden mempunyai latar belakang kesukuan dan karakteristik pembelajaran yang berbeda, namun struktur masyarakat Kalbar yang majemuk, yang diperkaya dengan kebudayaan Tionghoa yang sudah menjadi salah satu khasanah budaya Kalimantan Barat, letak geografis Pontianak yang berbatasan langsung dengan Kuching, Malaysia, dan dekat dengan Singapura serta arus investasi RRT yang signifikan di Kalimantan Barat, mendorong motivasi ekstrinsik berubah menjadi suatu kebutuhan, yang kemudian berasimilasi dengan motivasi instrinsik, mendorong tumbuhnya motivasi yang lebih kuat. Meskipun pada saat ini belum semua pelajar dan mahasiswa terbiasa untuk menggunakan Bahasa Mandarin dan belum menguasai Bahasa Mandarin secara maksimal, namun dengan adanya motivasi yang kuat dari dalam diri peserta didik dan dukungan faktor-faktor pembelajaran lainnya, diharapkan lebih banyak pelajar dan mahasiswa di Pontianak yang mampu menguasai Bahasa Mandarin sebagai salah satu kompetensi diri untuk menang dalam persaingan global.

\section{DAFTAR PUSTAKA}

Anastasia Sri Mendari. Aplikasi Teori Hierarki Kebutuhan Maslow Dalam Meningkatkan Motivasi Belajar Mahasiswa. Widya Warta No. 01 Tahun XXXIV / Januari 2010. 
Arends, Richard I. 2009. Learning To Teach. Mc. Graw Hill Higher Education. New York.

Lin Xin. Thesis : The Studying on the Learning Motivation of the Indonesian Learners of Chinese - Taking the Chinese Department of Buna Mulia University, Indonesia an example. Guangxi Normal University. 2013.4.

Lü Peishan. Thesis : Reseacrh of Learning Motivation of Chinese Language in Senior High School Students in Bandung. Hebei Normal University. 2013.6.

Ormrod, Jeanne Ellis. 2009. Psikologi Pendidikan - Membantu Siswa Tumbuh dan Berkembang, Edisi Ke-enam. Penerbit Erlangga. Jakarta.

Tang Yan'Er. 2003. Huawen Jiaoyu Xinlixue. Jinan University Press. Guangzhou.

Yi Ying, Muhammad Nanang Suprayogi, Evi Afifah Hurriyati. Motivasi Belajar Bahasa Mandarin Sebagai Bahasa Kedua. Humaniora Vol 4 No.2 Oktober 2013: 1345-1355.

Yovita. Thesis : Bunda Mulia University of Chinese Language Students Learning Motivation. Hebei Normal University. 2014.7. 
